\title{
KECEMASAN PADA SISWA KELAS 1 \\ DI SMP DHARMA WANITA 9 TAMAN SIDOARJO: \\ PENGEMBANGAN INSTRUMEN
}

\author{
Ummu Umayyah \\ ummuumayyah06@gmail.com \\ Uin Sunan Ampel Surabaya \\ Aisyah Salsabila \\ syahsal2706@gmail.com \\ Uin Sunan Ampel Surabaya
}

\begin{abstract}
This quantitative research was carried out to develop anxiety instrument, from grand theory, aspect become indicators to statements item that represent theoritical constract of anxiety, In the forms of blueprint. The sampling technique used purposive sampling, subject of this research are 98 respondent of junior high school in first years. This study developed an anxiety instrument using aspects of Rosenhan and Seligman. Data analysis using SPSS. Validity test proves that item 6 and 20 falls because of less than 0,300 . Item's $1,2,3,4,5,7,8,9,10,11,12,13,14,15,16,17,18,21$ is valid because upper than 0,300 . In reliability test was found a number 0,871 that shows the data is reliable.
\end{abstract}

Kata Kunci: Uji Validitas, Uji Reliabilitas, Instrumen Kecemasan, Pengembangan Instrumen

\section{Kajian Teori}

Anxiety atau kecemasan menurut Schwartz kecemasan berarti penyempitan atau pencekikan, kecemasan mirip dengan rasa takut dengan fokus yang kurang spesifik sedangkan ketakutan biasanya respon terhadap beberapa ancaman langsung yang ditandai dengan kekhawatiran tentang bahaya tidak terduga yang ada dimasa depan. Kecemasan merupakan keadaan emosi negatif yang ditandai dengan adanya firasat dan somatik ketegangan, seperti hati berdetak kencang, berkeringat, kesulitan bernafas. ${ }^{1}$

Dalam teori kecemasan yang diungkapkan oleh Gufron dan Risnawati kecemasan merupakan pengalaman subyektif yang tidak menyenangkan mengenai kekhawatiran atau ketegangan berupa perasaan cemas, tegang, dan

\footnotetext{
1 Schwartz, Steven. 2000. Abnormal psychology: a discovery approach. California: Mayfield Publishing Company
} 
emosi yang dialami seseorang. ${ }^{2}$

Kecemasan bisa dikendalikan dengan adanya kontrol diri pada diri seseorang. Kontrol diri berkaitan dengan bagai-mana individu mengendalikan emosi serta dorongan-dorongan dari dalam dirinya ${ }^{3}$.

Kecemasan adalah suatu keadaan emosional yang mempunyai ciri keterangsangan fisiologis, perasaan tegang yang tidak menyenangkan, dan perasaan aprehensif bahwa sesuatu yang buruk akan terjadi. ${ }^{4}$

Daradjat menyatakan bahwa kecemasan memiliki segi yang di luar kesadaran dan tidak jelas, seperti takut tanpa mengetahui sebabnya dan tidak bisa menghindari perasaan yang tidak menyenangkan. Kecemasan muncul karena beberapa situasi yang mengancam diri manusia sebagai makhluk sosial. 5

Menurut Sarlito kecemasan merupakan takut yang tidak jelas objeknya dan tidak jelas pula alasannya. ${ }^{6}$

Berdasarkan pendapat beberapa tokoh tersebut dapat diambil kesimpulan bahwa kecemasan adalah perasaan ketakutan yang tidak diketahui sebabnya.

\section{Definisi Operasional}

Kecemasan merupakan suatu kondisi yang meliputi rasa khawatir, gugup, keringat yang berlebihan dan tidak bisa mengontrol semua yang di rasakannya sehingga kecemasan selalu meningkat jika merasa pada saat situasi yang tidak nyaman.

\section{Aspek-Aspek Kecemasan}

Menurut Daradjat (1990), aspek-aspek kecemasan terbagi menjadi dua bentuk, yaitu: a) fisiologis: bentuk reaksi fisiologis berupa detak jantung meningkat, pencernaan tidak teratur, keringat berlebihan, ujung-ujung jari terasa dingin, sering buang air kecil, tidur tidak nyenyak, kepala pusing, nafsu makan hilang dan sesak nafas. b) psikologis: yang terbagi menjadi dua bentuk, yaitu aspek afektif: Termasuk dalam aspek ini antara lain: takut, merasa dirinya akan ditimpa bahaya. ${ }^{7}$

Aspek-aspek lain menurut Rosenhan dan Seligman (1989) meliputi: a) somatik, yaitu reaksi tubuh terhadap bahaya; b) kognitif, yaitu respon terhadap kecemasan dalam pikiran manusia; c) emosi, yaitu perasaan manusia

\footnotetext{
${ }^{2}$ Nur, G. \& Risnawita, Rini. 2014. Teori-teori psikologi. Jogjakarta: Ar-Ruzz Media.

${ }^{3}$ Hurlock, EB. 1997. Psikologi Perkembangan: Suatu Pendekatan Sepanjang Rentang Kehidupan. Alih Bahasa Istiwidayanti. Jakarta:Penerbit Erlangga.

${ }^{4}$ Nevid, Jeffrey dkk. 2005. Psikologi abnormal. Edisi kelima. Jilid 1. Jakarta: Erlangga.

${ }^{5}$ Daradjat, Z. 1990. Kesehatan Mental. Jakarta: Gunung Agung.

${ }^{6}$ Wirawan, S.S. 2012. Pengantar Psikologi Umum. Jakarta: Rajawali Press.

${ }^{7}$ Idem
} 
yang mengakibatkan individu secara teru-menerus khawatir, merasa takut terhadap bahaya yang meng-ancam; dan d) perilaku, yaitu reaksi dalam bentuk perilaku manusia terhadap ancaman dengan menghindar atau menyerang. ${ }^{8}$

Shah dalam Gufron dan Risnawati membagi kecemasan menjadi tiga aspek, a) aspek fisik, b) aspek emosional, c) aspek mental atau kognitif. ${ }^{9}$

\section{Jenis Kecemasan}

Menurut Spilberger kecemasan memiliki dua bentuk yakni, a) trait anxiety yaitu adanya rasa khawatir dan terancam yang menghinggapi diri seseorang dalam kondisi tidak berdaya. b) state anxiety yaitu kondisi emosional dan keadaan sementara pada diri individu karena merasa tegang atau khawatir yang dirasakan secara subjektif. ${ }^{10}$

\section{Metode Penelitian}

Penelitian kuantitatif ini bertujuan untuk mengembangkan instrumen penelitian, dengan menggunakan variabel kecemasan pada anak SMP kelas 1.

\section{Teknik Sampling}

Populasi dalam penelitian ini ialah seluruh siswa kelas 1 SMP Dharma Wanita 9 Taman. Metode pengambilan sampel dalam penelitian ini ialah purposive sampling, yaitu teknik pengambilan sampel yang kriterianya sesuai dengan keinginan atau tujuan peneliti. Besar sampel yang diambil dalam penelitian ini yaitu dengan populasi sebesar 120 siswa.

Peneliti menggunakan 98 sampel untuk mengantisipasi besarnya kesalahan pada penelitian ini. Pengumpulan data dilakukan dengan menggunakan instrumen yang dibuat melalui definisi operasional, mengembangan aitem melalui aspek Rosenhan dan Seligman, dan kemudian data yang telah dikumpulkan melalui kuesioner selanjutnya dicari validitas aitem dan nilai reliabilitas atau keajegan instrumen tersebut menggunakan program SPSS versi 16.0.

\section{BluePrint Instrument}

Berikut bluprint instrumen yang menerangkan proses pengembangan instrumen kecemasan.

\footnotetext{
${ }^{8}$ Rosenhan, D. L \&Seligman, E. P. 1989. Abnormal Psycology, 2th edition. New york: WW. Norton \& Company Inc.

${ }^{9}$ Idem

${ }^{10}$ Safaria, T \& Eka, N. 2012. Manajemen emosi: sebuah panduan cerdas bagaimana mengelola emosi positif dalam hidup anda. Jakarta: Bumi Aksara.
} 
Table 1

Bluprint Instrumen

\begin{tabular}{|c|c|c|}
\hline Aspek & Indikator & Aitem \\
\hline \multirow{4}{*}{$\begin{array}{l}\text { Aspek Somatik } \\
\text { (reaksi tubuh } \\
\text { terhadap bahaya) }\end{array}$} & $\begin{array}{l}\text { Keringat } \\
\text { berlebihan }\end{array}$ & $\begin{array}{l}\text { Saya mudah berkeringat ketika } \\
\text { menghadapi hal yang baru }\end{array}$ \\
\hline & & $\begin{array}{l}\text { saya berkeringat ketika saya } \\
\text { berbicara di depan umum. } \\
\text { saya mudah berkeringat dingin } \\
\text { saat menghadapi ujian. }\end{array}$ \\
\hline & $\begin{array}{l}\text { Sakit kepala } \\
\text { atau perut. }\end{array}$ & $\begin{array}{l}\text { saya tiba-tiba merasa mual ketika } \\
\text { ada kabar ujian mendadak } \\
\text { saya merasa pusing ketika diberi } \\
\text { tugas deadline. } \\
\text { saya akan merasa pusing ketika } \\
\text { tugas tak kunjung selesai. }\end{array}$ \\
\hline & $\begin{array}{l}\text { Denyut jantung } \\
\text { berdetak lebih } \\
\text { cepat }\end{array}$ & $\begin{array}{l}\text { Jantung saya berdetak kencang } \\
\text { ketika menghadapi guru yang } \\
\text { killer. } \\
\text { Saya merasa jantung saya berdetak } \\
\text { kencang saat melihat kecelakaan. } \\
\text { Jika saya cemas maka jantung saya } \\
\text { berdetak lebih kencang. }\end{array}$ \\
\hline \multirow[t]{3}{*}{$\begin{array}{l}\text { Aspek afektif } \\
\text { (aspek ini antara lain } \\
\text { takut, merasa dirinya } \\
\text { akan ditimpa bahaya) }\end{array}$} & $\begin{array}{l}\text { Membandingka } \\
\mathrm{n} \text { diri sendiri } \\
\text { secara negatif } \\
\text { dengan orang } \\
\text { lain }\end{array}$ & $\begin{array}{l}\text { Saya selalu membandingkan diri } \\
\text { saya dengan orang lain. }\end{array}$ \\
\hline & & $\begin{array}{l}\text { Saya mudah pasrah ketika teman } \\
\text { saya sudah menyelesaikan } \\
\text { tugasnya. } \\
\text { Saya merasa bahwa orang lain } \\
\text { mampu melakukan sesuatu secara } \\
\text { lebih baik daripada apa yang } \\
\text { mampu saya lakukan. }\end{array}$ \\
\hline & $\begin{array}{l}\text { Membuat } \\
\text { pernyatan diri } \\
\text { yang negatif }\end{array}$ & Saya mudah putus asa \\
\hline
\end{tabular}


Aspek emosi

(perasaan manusia

yang mengakibatkan

individu secara teru-

menerus khawatir)
Saya takut orang lain tidak suka dengan saya.

Saya berfikir orang lain tidak dapat menerima kehadiran saya.

Merasa takut Saya merasa tidak bisa menerima terhadap resiko yang akan terjadi.

bahaya yang

mengancam.
Individu secara terus-menerus khawatir. saya merasa takut ketika ada orang asing yang menanyai.

Saya selalu was-was ketika ada orang lain sedang melihati saya Saya selalu mengkhawatirkan perkataan orang lain tentang saya.

saya minder ketika orang lain tau sifat saya.

saya sering merasa bahwa saya akan gagal dalam sesuatu yang saya lakukan.

Tabel 1 menunjukkan adanya 3 aspek menurut Rosenhan dan Seligman, yaitu aspek somatik, aspek afektif, dan aspek emosi yang di jadikan acuan pembuatan indikator aitem. Indikator aitem tersebut di jadikan acuan untuk pembuatan aitem pernyataan yang mewakili kontrak teoritik.

\section{Uji Validitas Aitem}

\section{Analisa Tabel 3 Uji Validitas}

Berdasarkan uji validitas yang telah dilakukan, didapatkan hasil sebagai berikut.

Scale Mean if Item Scale Variance if Item Corrected Item-Total Deleted Deleted Correlation

\begin{tabular}{llll}
\hline A1 & 97.51 & 231.315 & .489 \\
A2 & 97.34 & 230.206 & .450 \\
A3 & 97.74 & 233.256 & .407 \\
\hline
\end{tabular}




\begin{tabular}{llll}
\hline A4 & 97.66 & 231.539 & .473 \\
A5 & 97.96 & 230.144 & .536 \\
A6 & 97.96 & 235.269 & .275 \\
A7 & 97.84 & 232.452 & .414 \\
A8 & 97.63 & 235.111 & .303 \\
A9 & 97.39 & 232.491 & .405 \\
A10 & 98.14 & 230.166 & .503 \\
A11 & 98.06 & 229.079 & .554 \\
A12 & 97.33 & 227.223 & .588 \\
A13 & 97.40 & 227.410 & .535 \\
A14 & 97.26 & 222.902 & .611 \\
A15 & 97.87 & 230.534 & .531 \\
A16 & 97.21 & 231.165 & .459 \\
A17 & 97.68 & 227.949 & .577 \\
A18 & 227.964 & .533 \\
A19 & 97.88 & 231.691 & .415 \\
A20 & 97.70 & 235.231 & .277 \\
A21 & 97.09 & 235.934 & .329 \\
TOTAL1 & 96.94 & 60.469 & 1.000 \\
\hline
\end{tabular}

Aitem yang gugur yakni Aitem 6 dan Aitem 20, dikarenakan nilai Aitem 6 sejumlah 0,275 dan nilai Aitem 20 sejumlah 0,277 kurang dari 0,300. Aitem 1,2, $3,4,5,7,8,9,10,11,12,13,14,15,16,17,18,19,21$ dinyatakan valid karena melebihi dari 0.300 .

\section{Uji Reliabilitas}

Table 2 Uji Reliabilitas

Case Processing Summary

\begin{tabular}{llrr}
\hline & & & $\%$ \\
Cases & Valid & 97 & 100.0 \\
& Excluded & & \\
& Total & 97 & .0 \\
& & 97 & 100.0 \\
\hline
\end{tabular}

a. Listwise deletion based on all variables in the procedure. 


\begin{tabular}{|c|c|c|}
\hline \multicolumn{3}{|c|}{ Reliability Statistics } \\
\hline Cronbach's Alpha & $\begin{array}{l}\text { Cronbach's Alpha Based } \\
\text { on Standardized Items }\end{array}$ & Nof Items \\
\hline .736 & .871 & 19 \\
\hline
\end{tabular}

Interpretasi:

Pada Tabel 2 dikolom cronbach's Alpha didapati nilai 0,736 yakni nilai tersebut merupakan nilai reliabilitas tes secara keseluruhan, semakin besar nilainya berarti semakin reliabel.

\begin{tabular}{lll}
\hline Aitem & Cronbach's Alpha & Keterengan \\
\hline A1 & 0,725 & Valid \\
A2 & 0,725 & Valid \\
A3 & 0,728 & Valid \\
A4 & 0,726 & Valid \\
A5 & 0,724 & Valid \\
A7 & 0,727 & Valid \\
A8 & 0,730 & Valid \\
A9 & 0,727 & Valid \\
A10 & 0,724 & Valid \\
A11 & 0,722 & Valid \\
A12 & 0,720 & Valid \\
A13 & 0,721 & Valid \\
A14 & 0,715 & Valid \\
A15 & 0,724 & Valid \\
A16 & 0,725 & Valid \\
A17 & 0,721 & Valid \\
A18 & 0,721 & Valid \\
A19 & 0,726 & Valid \\
A21 & 0,731 & Valid \\
TOTAL & 0,871 & \\
\hline
\end{tabular}

\section{Pembahasan}

Penelitian kuantitatif ini peneliti menggunakan populasi siswa/i kelas 1 SMP Dharma Wanita 9 Taman, karena pada masa SMP tersebut mereka mempunyai rasa kecemasan karena menghadapi orang-orang baru dan lebih mandiri daripada masa SD. Dalam hasil validitas yang merupakan alat pengukur yang dipergunakan untuk mengukur dan mengkorelasikan antara 
skor yang diperoleh pada masing-masing aitem pertanyaan dengan skor total individu. Uji validitas dilakukan untuk menguji nilai validitas pada kuesioner dan data, dalam penelitian ini uji validitas hanya dilakukan pada 98 responden. Uji reliabilitas dilakukan terhadap aitem pertanyaan yang dinyatakan valid, reliabilitas merupakan syarat untuk tercapainya validitas suatu kuesioner dengan tujuan tertentu.

Dalam penelitian ini menggunakan teknik sampling purposive sampling karena dalam skala kecemasan ini tidak semua orang memiliki rasa kecemasan. Instrumen penelitian ini dikembangkan berdasarkan kontrak teoritik dari Rosenhan dan Seligman. Setelah disebarkan kuesioner diuji validitas dan reliabilitasnya dengan menggunakan SPSS 16.0

Berdasarkan hasil uji validitas ditemukan aitem yang gugur yaitu aitem 6 sejumlah 0,275 dan aitem 20 sejumlah 0,277 dikarenakan kurang dari standar yang ditentukan sejumlah 0,300. Aitem 1 sejumlah 0,489, Aitem 2 sejumlah 0,450, Aitem 3 sejumlah 0,407, Aitem 4 sejumlah 0,437, Aitem 5 sejumlah 0,536, Aitem 7 sejumlah 0,414, Aitem 8 sejumlah 0,303, Aitem 9 sejumlah 0,405, Aitem 10 sejumlah 0,503, Aitem 11 sejumlah 0,554, Aitem 12 sejumlah 0,588, Aitem 13 sejumlah 0,535, Aitem 14 sejumlah, Aitem 15 sejumlah 0,531, Aitem 16 sejumlah 0,459, Aitem 17 sejumlah 0,577, Aitem 18 sejumlah 0,533, Aitem 19 sejumlah 0,415, Aitem 21 sejumlah 0,329 nilainya melebihi dari 0,300. Setelah diketahui aitem yang sudah valid lalu dilakukan uji reliabilitas cronbach's alpha yaitu 0,871 karena hasil uji reliabilitas mendekati angka 1,00 maka aitem pada skala kecemasan tersebut dikatakan reliabel.

\section{Daftar Pustaka}

Azwar, Saifuddin. 2018. Reliabilitas dan Valibitas. Yogyakarta: Pustaka Pelajar.

Daradjat, Z. 1990. Kesehatan Mental. Jakarta: Gunung Agung.

Hurlock, EB. 1997. Psikologi Perkembangan: Suatu Pendekatan Sepanjang Rentang Kehidupan. Alih Bahasa Istiwidayanti. Jakarta:Penerbit Erlangga.

Triastuti, D., Sutikno, N., \& Risnawaty, W. 2009. Gambaran Kecemasan dan Strategi Penanganan Anak Didik Kasus Pembunuhan: Studi Kasus Andik yang Telah Memasuki Masa Asimilasi di Lapas Anak Pria Tangerang. Jurnal Arkhe Universitas Tarumanegara, 1, 31-39.

Rosenhan, D. L \& Seligman, E.P. 1989. Abnormal Psychology, 2th Edition. New York: W.W. Norton \& Company Inc.

Muhid, Abdul. 2019. Analisis Statistik 5 Langkah Praktis Analisis Statistik dengan SPSS for Windows. Sidoarjo: Zifatama Jawara.

Nevid, Jeffrey dkk. 2005. Psikologi abnormal. Edisi kelima. Jilid 1. Jakarta: 


\section{Erlangga.}

Nur, G. \& Risnawita, Rini. 2014. Teori-teori psikologi. Jogjakarta: Ar-Ruzz Media.

Safaria, T \& Eka, N. 2012. Manajemen emosi: sebuah panduan cerdas bagaimana mengelola emosi positif dalam hidup anda. Jakarta: Bumi Aksara.

Schwartz, Steven. 2000. Abnormal psychology: a discovery approach. California: Mayfield Publishing Company

Sugiyono. 2011. Metode Penelitian Kuantitatif, Kualitatif, dan RED. Bandung: Penerbit Alfabeta.

Wagiran. 2015. Metode Penelitian Pendidikan : Teori dan Implementasi. Yogyakarta: Penerbit Deepublish.

Wirawan, S.S. 2012. Pengantar Psikologi Umum. Jakarta: Rajawali Press. 
